\title{
37. INDEX PROPERTIES AND COMPRESSIONAL-WAVE VELOCITY VARIATIONS AND CORRELATIONS FOR LEG $124^{1}$
}

\author{
Dwayne D. Tannant ${ }^{2}$
}

\begin{abstract}
Measurements of compressional-wave velocity and index properties were routinely taken from sediment and rock that was cored within the Sulu and Celebes Seas during Leg 124. The variations in porosity, wet-bulk density, grain density, compressional-wave velocity, and acoustic impedance are related to changes in the degree of lithification, sediment type, and basement rocks. Inflection points in porosity profiles or porosities less than about $50 \%$ may indicate the onset of lithification. Porosities below $50 \%$ have a control on compressional-wave velocity and acoustic impedance profiles. The physical properties correlate with downhole geophysics and seismic profiles.
\end{abstract}

\section{INTRODUCTION}

Five different sites in the Sulu and Celebes Seas were drilled during Leg 124 of the Ocean Drilling Program. The strata in these basins comprises a wide range of lithologies including pelagic, hemipelagic, and volcaniclastic sediment, turbidites, and nannofossil marls. Drilling was performed using three coring systems. The advanced piston corer (APC) was used in the softer sediment near the seafloor and provided good recovery and the least core disturbance. In response to increased induration, an extended core barrel (XCB) system was used to core deeper sediment. The XCB yielded reduced recovery due to interbeds of silt, hard chalk, sand, and ash. Sample disturbance increased noticeably with the $\mathrm{XCB}$, and extensive core biscuiting occurred. Coring in the deepest, lithified sediment and basaltic basement rock was completed with a rotary core barrel (RCB). Drilling during Leg 124 resulted in the recovery of $1922 \mathrm{~m}$ of sediment core. Basaltic rock was cored at three sites; a total of about $200 \mathrm{~m}$ was recovered.

Index properties were determined for discrete samples taken from sections of split core. The index properties include bulk density, grain density, porosity, water content, and void ratio. Because void ratio and water content are directly related to porosity, only porosity is examined in this paper. In addition to index-property determinations, measurements of compressional-wave velocity were also taken on selected discrete samples using a Hamilton Frame apparatus (Boyce, 1976). This paper examines the relationships between porosity, wet-bulk density, grain density, and Hamilton Frame compressional-wave velocities measured during Leg 124 . Bulk density and velocity data from Site 768 are used to generate an acoustic impedance profile. Whereas the data presented in the Initial Reports volume (Rangin, Silver, von Breymann, et al., 1990) were site specific, in this paper the data are used to establish some general correlations between the index properties and velocity that give insight into the seismic response of the sediments and the degree of consolidation and lithification of the sediments at different depths.

${ }^{1}$ Silver, E. A., Rangin, C., von Breymann, M. T., et al., 1991. Proc. ODP, Sci. Results, 124: College Station, TX (Ocean Drilling Program).

${ }^{2}$ Geomechanics Research Centre, Laurentian University, Sudbury, Ontario, Canada P3E 2C6.
The measured properties can also provide verification of geophysical data.

\section{EXPERIMENTAL TECHNIQUES AND DATA}

All data presented in this paper were obtained in the on-board laboratory at atmospheric pressure and room temperature. The data are laboratory-measured values and have not been corrected (back-calculated) to represent the in-situ values. The measurements do not account for the increase in volume (and porosity) caused by the removal of the samples from the confining stress of the overlying sediments. However, the index properties have been corrected for salt content. The testing and data reduction methods that were employed have been previously established on board the JOIDES Resolution (Boyce, 1976) and are detailed in Rangin, Silver, von Breymann, et al. (1990).

Although the measurements may not accurately reflect the in-situ properties due to sample disturbance, the relative changes in properties and relationships between properties can indicate trends and variations in characteristics of the sediments and basement rocks. Furthermore, any systematic errors introduced during sampling and testing should have minimal effect on relative variations in the measured properties.

Compressional-wave velocities could not be measured for most nonindurated sediments encountered in the upper part of the sediment column. However, when stiffer, more indurated sediments were present, velocity measurements were obtained. Hence, the velocity data may fail to reflect the dominant lithologies because it is skewed to sediment types upon which velocity testing was successful. As the sediment became more lithified, deeper in the section, the bias in velocity measurement was reduced because all sediment types tended to yield Hamilton Frame velocities.

\section{VELOCITY-INDEX PROPERTY RELATIONS}

Figure 1 illustrates the relationships between compressional-wave velocity and porosity, wet-bulk density, and grain density. Velocities below $3.0 \mathrm{~km} / \mathrm{s}$ generally reflect tests performed on sedimentary lithologies; however, occasional thin, dense, carbonate-rich turbidite deposits, well-cemented sandstones, and well-lithified tuff and lapillistone gave velocities as high as $5.0 \mathrm{~km} / \mathrm{s}$. Velocities in the basement rock range from a low of $3.0 \mathrm{~km} / \mathrm{s}$ in the weathered pillow basalts to a high of $5.0-5.2 \mathrm{~km} / \mathrm{s}$ in the sills. 


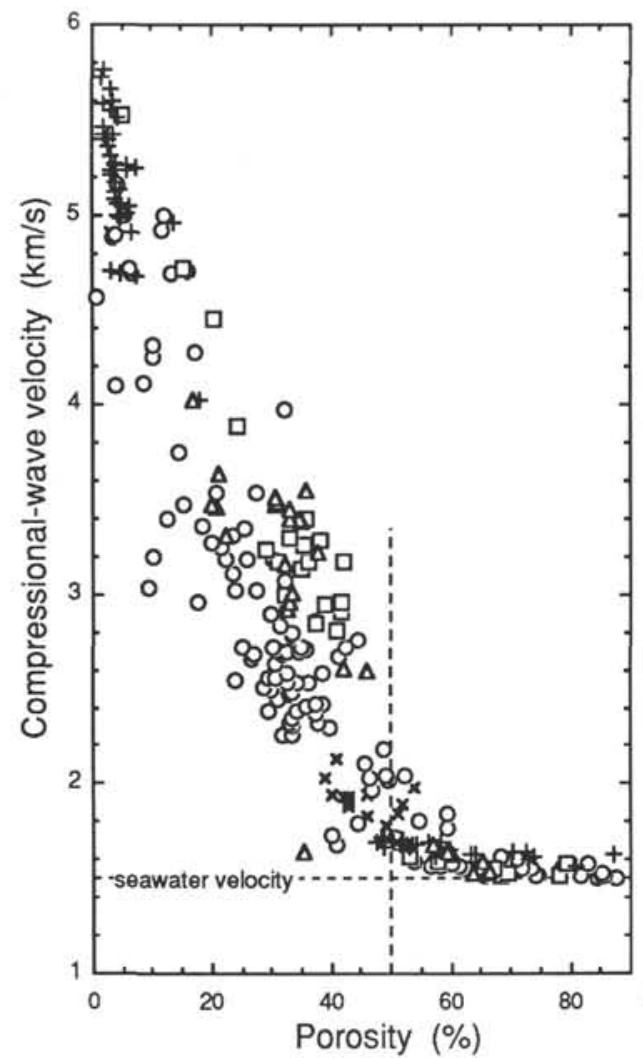

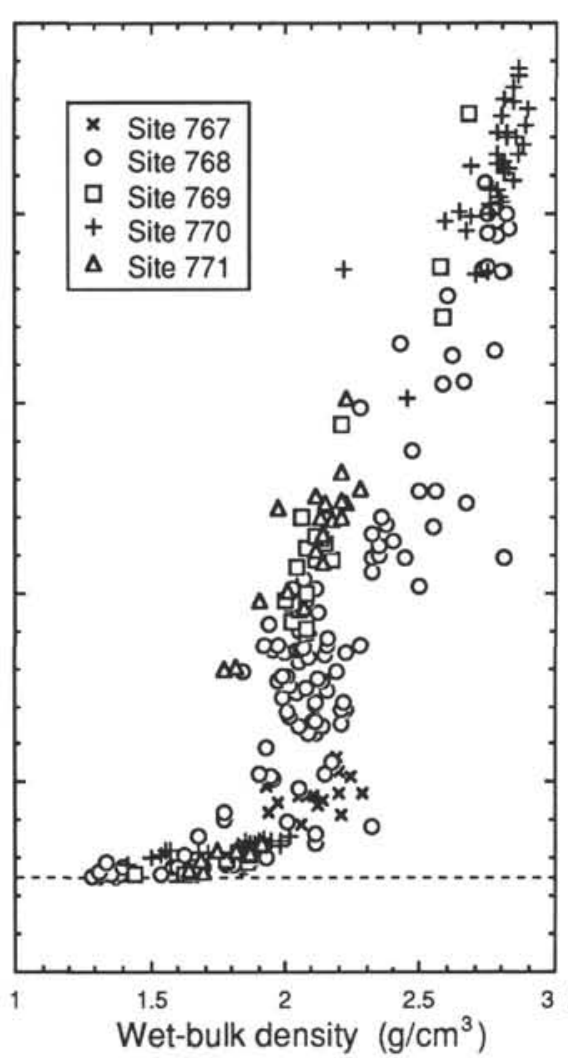

C

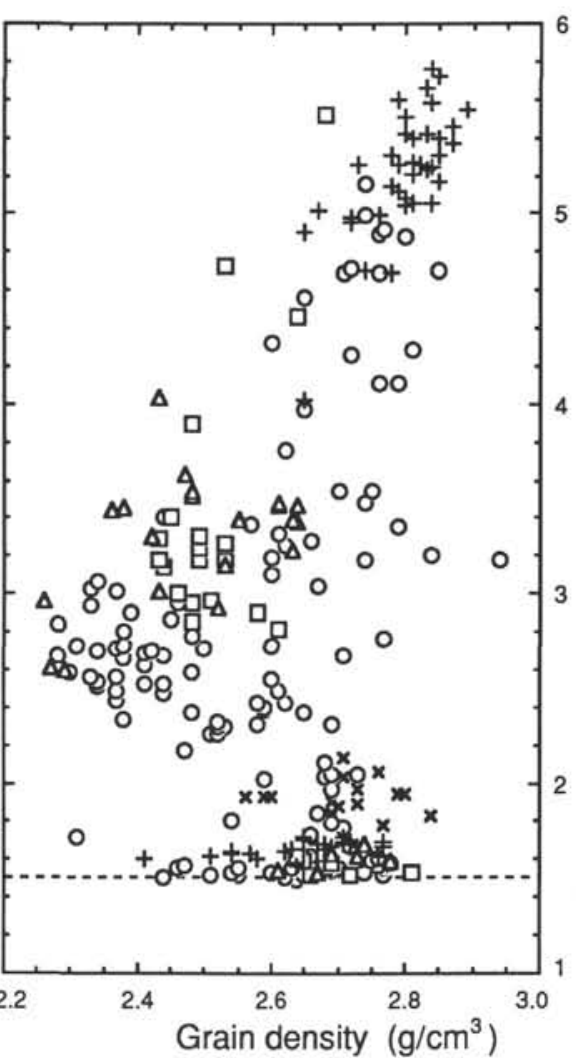

Figure 1. Compressional-wave velocity vs. A. Porosity, B. Wet-bulk density, and C. Grain density. All sediment and rock samples tested during Leg 124 are plotted. Open symbols represent data from the Sulu Sea sites, the other symbols are for Celebes Sea data. The vertical dashed line at $50 \%$ porosity marks the transition between porosity-dependent and porosity-independent compressional-wave velocities.

Figure 1A shows a transition between velocities that are dependent on porosity for porosities less than $50 \%$, to an essentially constant velocity at porosities greater than about $50 \%$. This transition marks the change from a fluid-dominated system of relatively unconsolidated sediment particles to a matrix-dominated system of partially lithified sediment. The consistent velocities, near $1.5 \mathrm{~km} / \mathrm{s}$, at porosities above $50 \%$ are primarily due to measurement of the velocity through seawater in the sample. The dramatic increase in velocity as the porosity decreases below $50 \%$ is a manifestation of the lithification of the sediments. As the sediment is buried, bulk density, grain-to-grain contacts, and cementing between grains increase. Both the bulk modulus and the rigidity of the material increase, thereby increasing the compressional-wave velocity through the material.

Figure 1B illustrates that the compressional-wave velocity is also dependent on the wet-bulk density. Wet-bulk density of a sample is a function of its porosity and grain density. Figure $1 \mathrm{C}$ shows little correlation between grain density and velocity. Therefore, the variation in porosity dominates the bulk density, and porosities less than about $50 \%$ also control the compressional-wave velocity of the sample.

The grain density of a sediment or rock is dominated by its mineralogy. The variations in grain density shown in Figure $1 \mathrm{C}$ reflect the varying lithologies. Ash and tuff yield low values, while the higher values come from terrigenous and pelagic sediment and the basalts. For example, the cluster of low grain densities measured at Site 768 corresponds to samples taken from rhyolitic to dacite pyroclastic flows and redeposited vitric tuffs. Although there is a wide variety of lithologies represented in the data from the Sulu and Celebes Seas, with grain densities having a $0.6 \mathrm{~g} / \mathrm{cm}^{3}$ range of values (Fig. 1C), the bulk densities vary by over $1.6 \mathrm{~g} / \mathrm{cm}^{3}$ (Fig. 1B).

Given that porosities less than $50 \%$ indicate a transition to porosity-dependent compressional-wave velocity, one can estimate the depth to sediments displaying greater lithification and hence, the depth below which potential seismic reflection horizons may occur. Figure 2 presents a compilation of all porosity measurements taken in the Sulu Sea sediments. At Sites 768 and 769 , the approximate transition depth corresponding to a $50 \%$ porosity is shown by the horizontal dashed lines in Figure 2. At Site 771, the shallower depth of sediments limited porosities to greater than $50 \%$. Disregarding the different sediment types found at each site, it appears that the transition depth varies from 280 mbsf (Site 769) to $330 \mathrm{mbsf}$ (Site 768) in the Sulu Sea. Hamilton (1976) found that an inflection point in the porosity vs. depth curve may indicate the depth at which sediments begin to show signs of lithification. The depth determined from velocity-porosity considerations corresponds well with an inflection point in the porosity profile for Site 768, which occurs at about 320 mbsf. Distinct inflection points do not exist in the porosity profiles at the other Sulu Sea sites, possibly due to lack of lithified sediments at greater depths.

\section{ACOUSTIC IMPEDANCE AT SITE 768}

The acoustic impedance of a medium determines the amount of sound energy reflected when sound passes from 


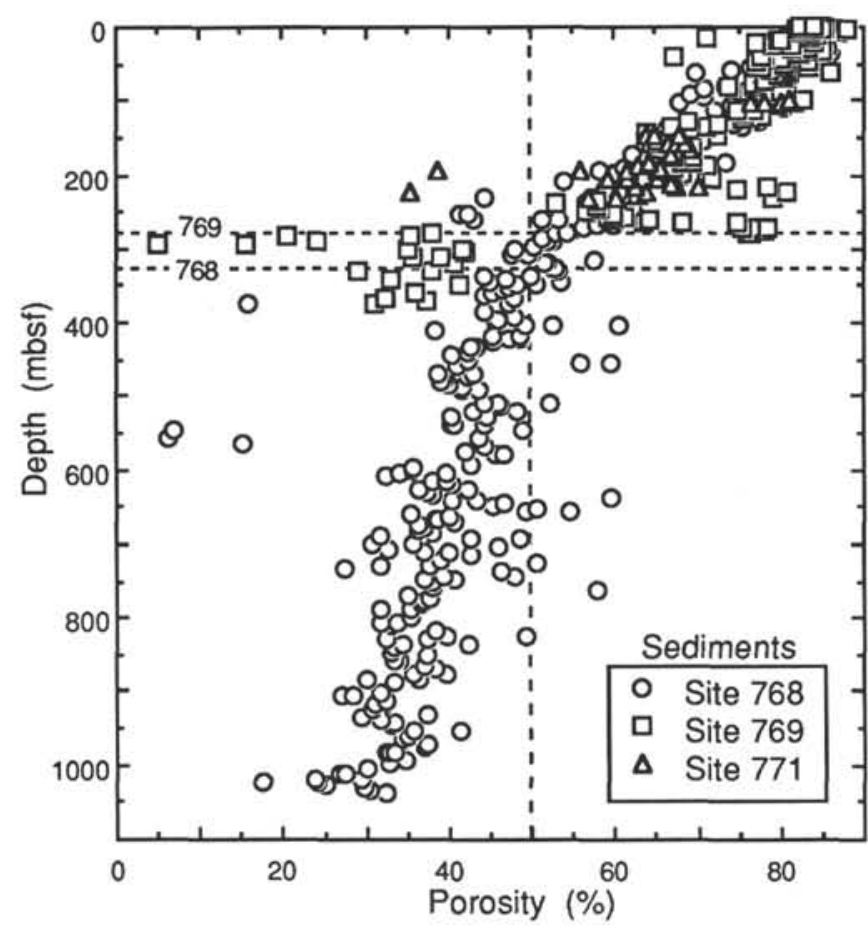

Figure 2. Porosity vs. depth below seafloor at the Sulu Sea sites. The dashed line at $50 \%$ porosity is used to estimate the depths to the transition from unlithified to lithified sediment at Sites 768 and 769.

one medium to another of different impedance. The acoustic impedance of a sediment is governed by the product of velocity and density. Therefore, the interaction between velocity and bulk density influences seismic stratigraphy. Of all sites, Site 768 supplied the most extensive set of physicalproperty data, and the acoustic impedance profile at this site is given in Figure 3. The bulk-density and velocity profiles and general lithologies at Site 768 are also given in Figure 3.

In softer, unconsolidated sediment with porosities greater than approximately $50 \%$, at depths of 0 to $330 \mathrm{mbsf}$, the bulk density increases gradually with depth (Fig. 3A), and velocity is essentially constant (Fig. 3B). Thus, no seismic reflections should be produced in the upper sections of the sediment column. However, between 350 and 750 mbsf a few, anomalously high density sediments occur that correspond to nonrepresentative thin, indurated deposits composed of a calcitecemented quartz sandstone and a dolomitized carbonate turbidite. The cementing and induration of these specific deposits has also resulted in high velocities and hence, higher acoustic impedances. If we neglect these restricted deposits, the upper 300 or $400 \mathrm{~m}$ of sediment display a uniform increase in density with depth. The trends in the density data are mimicked by the acoustic impedance data. Based on the absence of pronounced acoustic impedance contrasts above about $600 \mathrm{mbsf}$, one would expect that no strong seismic reflectors would be present in this interval. However, the seismic profiles showed a high-amplitude reflector near 110 mbsf (Rangin, Silver, von Breymann, et al., 1990). Although not apparent at the resolution of Figure $3 \mathrm{~A}$, a $0.1-\mathrm{g} / \mathrm{cm}^{3}$ decrease in bulk density and a change in the density gradient occurs at 115 mbsf. This change in density (which roughly corresponds to a change in lithology from nannofossil marls above 120 mbsf to clay and silty clay below) may account for the observed seismic reflection.
At Site 768 the middle part of the sediment column, between 350 and $800 \mathrm{mbsf}$, is composed mainly of alternating beds of clay and silt (Rangin, Silver, von Breymann, et al., 1990). The more clay-rich lithologies become increasingly consolidated downward, and below 350 mbsf the clays, silty clays, and clayey silts become claystone, silty claystone, and clayey siltstone. The consolidation and partial lithification of the sediment is reflected by lower porosities and higher compressional-wave velocities. The increased variation in the acoustic impedance of the deeper sediment is attributed to variations in the degree of lithification and fluctuations in sediment type between turbidites and hemipelagic clays. These variations are probably associated with the parallel, flat-lying seismic reflectors observed in the seismic profiles of the area (Rangin, Silver, von Breymann, et al., 1990).

Below the interbedded claystones and sandstones at Site 768 lie thick deposits of pyroclastic material (Rangin, Silver, von Breymann, et al., 1990). Grain densities for the vitric tuffs and lapillistones ranged from 2.3 to $2.5 \mathrm{~g} / \mathrm{cm}^{3}$, which is much lower than densities for the other sediments (Fig. 1C). The bulk densities for the tuffs are low $\left(2.0 \mathrm{~g} / \mathrm{cm}^{3}\right)$ relative to the claystones $\left(2.15 \mathrm{~g} / \mathrm{cm}^{3}\right)$ above and below the tuffs. However, the acoustic impedance shows little distinction between the tuffs and claystones because the tuffs had slightly higher velocities that counteracted their lower bulk densities.

The grain densities for the tuffs at Site 768, based on downhole neutron and density logs, were 2.65 to $2.7 \mathrm{~g} / \mathrm{cm}^{3}$. These values are much higher than those determined on board. The difference may be attributed to the logs detecting more water in the tuff than was removable by freeze-drying the samples during index-property testing. The unliberated water may occur as bound water in the clays and glass and as pore water in nonpermeable pumice. Aside from this difference, the downhole geophysical logs at Site 768 are in close agreement with the physical properties determined on discrete samples (Rangin, Silver, von Breymann, et al., 1990).

Pillow basalts were encountered at 1047 mbsf. The contact between the basalts and the overlying claystones and tuffs is made clearly evident by a sudden increase in acoustic impedance (Fig. 3C). A further, much larger jump in acoustic impedance occurs at a contact between the pillow basalts and a dolerite sill at 1148 mbsf. The pillow basalts were weathered and have compressional-wave velocities of 3.0 to $3.5 \mathrm{~km} / \mathrm{s}$ that are typical for a weathered basalt. The sills have much higher velocities, ranging between 4.1 and $5.2 \mathrm{~km} / \mathrm{s}$, and higher densities than the pillow basalts. These sudden increases in acoustic impedance are consistent with the seismic profile at Site 768 (Rangin, Silver, von Breymann, et al., 1990), which clearly shows a high-amplitude seismic reflector at the contact between the sedimentary sequence and the pillow basalts and a second reflector at the basalt-sill contact.

As both bulk density and velocity are influenced by porosity, one would expect porosity to have a controlling influence on acoustic impedance. Figure 4 shows the relationship between porosity and acoustic impedance at Site 768. Clearly, porosity is affecting the acoustic impedance, especially for porosities less than roughly $50 \%$. As porosity decreases the acoustic impedance increases.

\section{CONCLUSIONS}

Variations and trends in porosity are useful for estimating the depth to consolidated or lithified sediment. For example, in the Sulu Sea the depth to lithified sediment was estimated to vary between 280 mbsf (Site 769) and 330 mbsf (Site 768) based on porosities less than $50 \%$ and an inflection point in a 
A

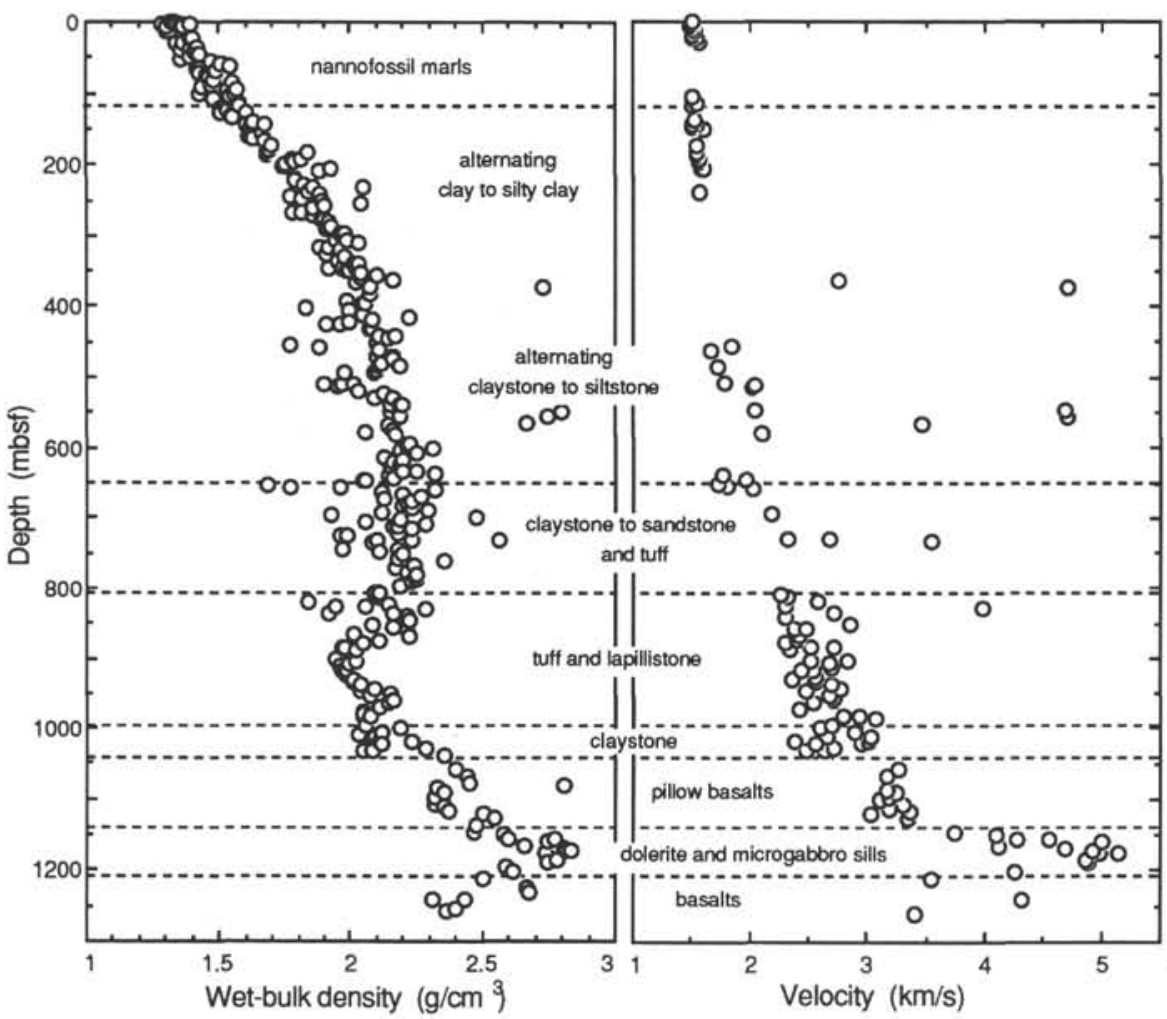

C

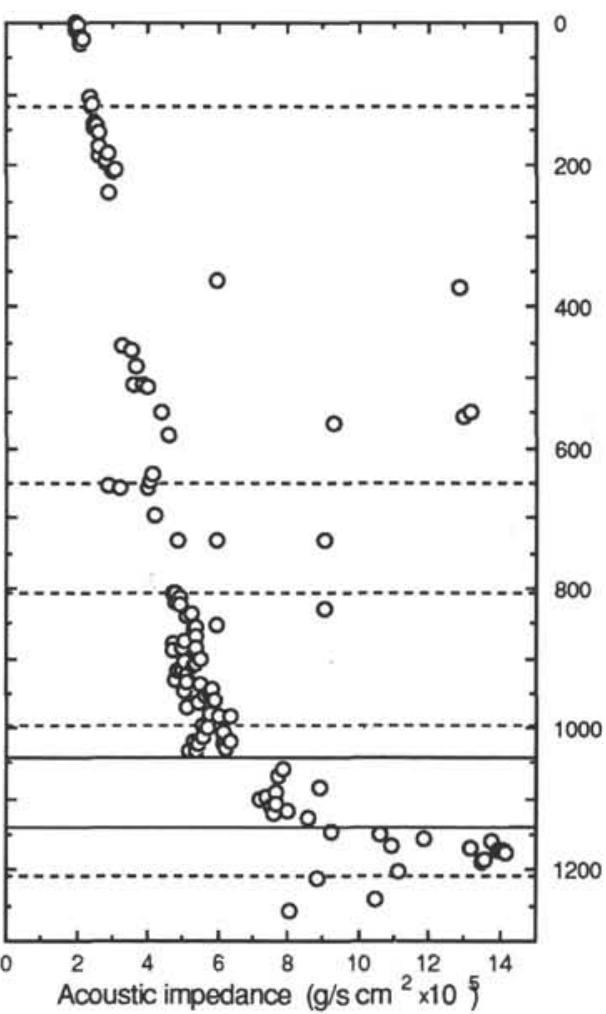

Figure 3. A. Wet-bulk density, B. Compressional-wave velocity, and C. Acoustic impedance vs. depth below seafloor at Site 768. General lithological units are delineated by horizontal dashed lines. Prominent acoustic impedance contrasts are indicated by two horizontal solid lines.

porosity profile. These depths are similar to depths determined from visual descriptions of the core.

Compressional-wave velocity is nearly constant in the upper, poorly consolidated sediments. However, once the sediment consolidates to a porosity below about $50 \%$, the velocity begins to increase. Variations in the index properties correlate well with changes in lithology, and match data obtained from downhole geophysical logging. Acoustic impedance profiles constructed from the bulk density and velocity data can indicate the location of seismic reflection horizons. At Site 768 the acoustic impedance profile showed strong contrasts at contacts between the sediments and basalts and between the basalts and sills. These contacts generated strong reflectors on the seismic profile.

\section{REFERENCES}

Boyce, R. E., 1976. Definitions and laboratory techniques of compressional sound velocity parameters and wet-water content, wet-bulk density, and porosity parameters by gravimetric and gamma ray attenuation techniques. In Schlanger, S. O., Jackson, E. D., et al., Init. Repts. DSDP, 33: Washington (U.S. Govt. Printing Office), 931-958.

Hamilton, E. L., 1976. Variations of density and porosity with depth in deep-sea sediments. J. Sediment. Petrol., 46:280-300.

Rangin, C., Silver, E. A., von Breymann, M. T., et al., 1990. Proc. ODP, Init. Repts., 124: College Station, TX (Ocean Drilling Program).

Date of Inital Receipt: 13 February 1990 Date of Acceptance: 7 September 1990 Ms 124B-164

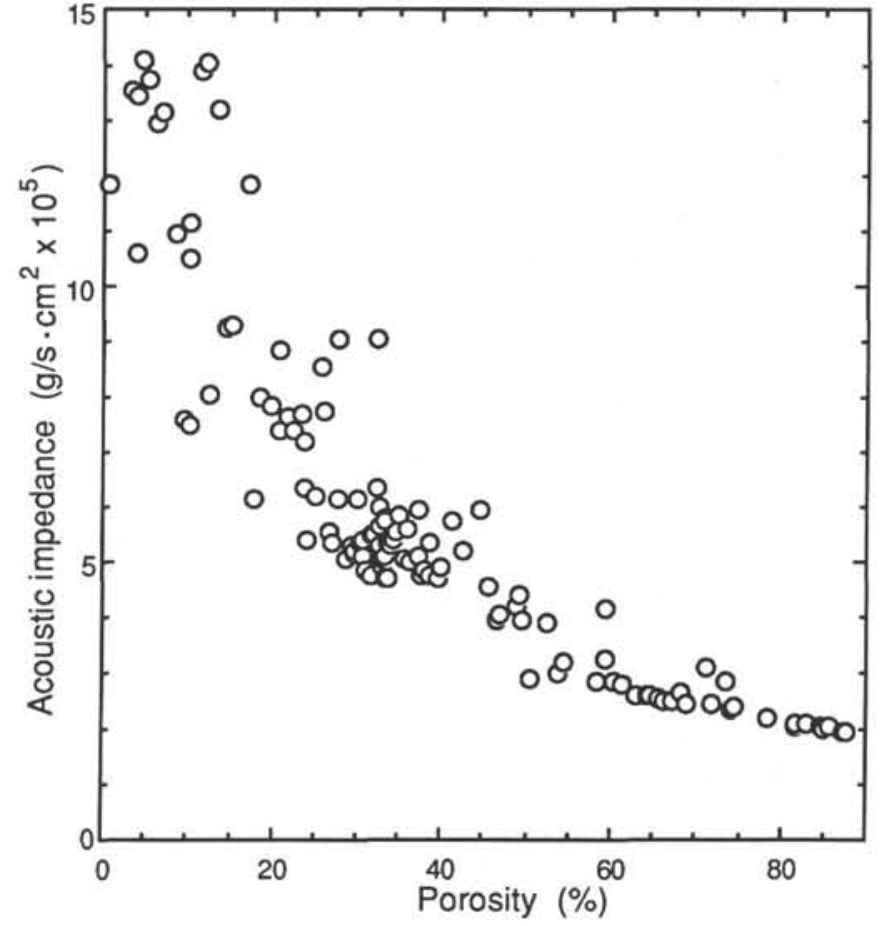

Figure 4. Acoustic impedance vs. porosity at Site 768 . 